Article

\title{
Preparation, Characterization and Evaluation of $\alpha$-Tocopherol Succinate-Modified Dextran Micelles as Potential Drug Carriers
}

\author{
Jingmou Yu ${ }^{1, *}$, Yunfeng Zhou ${ }^{1,2}$, Wencong Chen ${ }^{1}$, Jin Ren ${ }^{1}$, Lifang Zhang ${ }^{1}$, Lu Lu ${ }^{1}$, Gan Luo ${ }^{1}$ \\ and Hao Huang ${ }^{2, *}$ \\ Received: 18 August 2015 ; Accepted: 17 September 2015 ; Published: 28 September 2015 \\ Academic Editor: Jung Kwon (John) Oh \\ 1 School of Pharmacy and Life Sciences, Jiujiang University, 320 Xunyang East Road, Jiujiang 332000, China; \\ zhou768417683@gmail.com (Y.Z.); chen393787420@gmail.com (W.C.); yanjiushengrj@gmail.com (J.R.); \\ zhang524495632@gmail.com (L.Z.); yulu8275@gmail.com (L.L.); luo857084924@gmail.com (G.L.) \\ 2 School of Chemical and Biological Engneering, Yichun University, 576 Xuefu Road, Yichun 336000, China \\ * Correspondence: yjm1016@jju.edu.cn (J.Y.); jxychh2008@gmail.com (H.H.); \\ Tel./Fax: +86-792-8210-568 (J.Y.); +86-795-3201-985 (H.H.)
}

\begin{abstract}
In the present study, $\alpha$-tocopherol succinate (TOS) conjugated dextran (Dex-TOS) was synthesized and characterized by fourier transform infrared (FT-IR) spectroscopy, ${ }^{1} \mathrm{H}$ nuclear magnetic resonance $\left({ }^{1} \mathrm{H}\right.$ NMR), dynamic light scattering (DLS) and fluorescence spectroscopy. Dex-TOS could form nanoscaled micelles in aqueous medium. The critical micelle concentration $(\mathrm{CMC}$ ) is $0.0034 \mathrm{mg} / \mathrm{mL}$. Doxorubicin (Dox) was selected as a model drug. Dox-loaded Dex-TOS (Dex-TOS/Dox) micelles were prepared by a dialysis method. The size of Dex-TOS/Dox micelles increased from 295 to $325 \mathrm{~nm}$ with the Dox-loading content increasing from $4.21 \%$ to $8.12 \%$. The Dex-TOS/Dox micelles were almost spherical in shape, as determined by transmission electron microscopy (TEM). In vitro release demonstrated that Dox release from the micelles was in a sustained manner for up to $96 \mathrm{~h}$. The cellular uptake of Dex-TOS/Dox micelles in human nasopharyngeal epidermoid carcinoma (KB) cells is an endocytic process determined by confocal laser scanning microscopy (CLSM). Moreover, Dex-TOS/Dox micelles exhibited comparable cytotoxicity in contrast with doxorubicin hydrochloride. These results suggested that Dex-TOS micelles could be a promising carrier for drug delivery.
\end{abstract}

Keywords: dextran; $\alpha$-tocopherol succinate; polymeric micelles; doxorubicin; drug carrier

\section{Introduction}

Dextran, a polysaccharide consisting of 1, 6- and 1, 3-glucosidic linkages, has excellent water solubility and is widely used in medicine and biomedical devices [1-3]. Meanwhile, dextran and its derivatives have been extensively investigated for drug delivery vehicles due to biocompatibility, biodegradability and biological activities [4,5]. Hydrophobically modified dextrans have been successfully synthesized via derivatization of the primary hydroxyl groups. For example, Du and coworkers synthesized stearate-g-dextran (Dex-SA) amphiphiles [6]. Dox-loaded Dex-SA micelles could maintain the cytotoxicity of commercial doxorubicin injection against drug-sensitive tumor cells. Moreover, Dox-loaded Dex-SA micelles could effectively suppress the tumor growth and reduce the toxicity against animal body in nude mice bearing A549 human lung adenocarcinoma, compared with commercial doxorubicin injection. Hence, dextran-based polymeric amphiphiles have attracted significant attention as potential drug carriers. 
Amphiphilic copolymer is consisting of hydrophilic and hydrophobic segments. It can form micelles or self-assembled nanoparticles via the intra- and/or intermolecular interactions of hydrophobic domain in aqueous medium [7-10]. Micelles exhibit unique characteristics, such as unusual rheological features, thermodynamic stability and structure of a hydrophobic core and a hydrophilic shell. Especially, they can enhance the solubility of hydrophobic drug, preferentially accumulate in tumor tissue via the enhanced permeation and retention (EPR) effect and reduce systemic side effects [11,12]. Among these nanocarriers, much attention has still been paid to prepare biodegradable and nontoxic polymeric micelles.

$\alpha$-Tocopheryl succinate (TOS), one of the vitamin analogues, is a well-known hydrophobic molecule [13-15]. Furthermore, it has been approved as a pharmaceutical adjuvant or food supplement by the Food and Drug Administration and the European Medicine Agency [16]. Duhem et al. synthesized tocopherol succinate glycol chitosan (GC-TOS) conjugates. GC-TOS was non-cytotoxic at concentrations up to $10 \mathrm{mg} / \mathrm{mL}$ [17]. In addition, the result exhibited a 3.4-fold increase of the apparent permeation coefficient of ketoconazole across a Caco-2 cell monolayer. As reported by Mandracchia and co-workers, innovative inulin (INU)-vitamin E succinate (VITE) bioconjugates (INVITE) were synthesized and characterized [18]. Further, curcumin was selected as a model and curcumin-INVITE nanomicelles were prepared [19]. Pharmacokinetic studies on Balb/C mice exhibited the presence of curcumin up to $6 \mathrm{~h}$ in the blood, while "naked" curcumin is quickly removed from the bloodstream. More importantly, TOS can specifically destabilize cancer cell mitochondria but is nontoxic toward normal cells [20]. Considering the hydrophobicity and bioactive efficacy of TOS, we employed TOS chain to design functional copolymeric nanomaterial as the hydrophobic moieties.

In this study, the objective is to construct novel $\alpha$-tocopherol succinate conjugated dextran (Dex-TOS) nanocarriers. Dex-TOS conjugate was synthesized and characterized. Anticancer drug doxorubicin (Dox) was chosen as a model drug, which is widely used to treat different solid malignant tumors. Unfortunately, free Dox has severe side effects such as cardiotoxicity and myelosuppression in clinical application. The design and preparation of an excellent delivery system for effective deliver and release Dox into tumor cells is urgently needed. Therefore, Dox-loaded Dex-TOS micelles were prepared and characterized. Drug release from drug-loaded micelles was investigated. In vitro anti-tumor efficacy of Dox-loaded micelles was also studied in human nasopharyngeal epidermoid carcinoma (KB) cancer cells.

\section{Results and Discussion}

\subsection{Synthesis and Characterization of Dex-TOS Conjugate}

Dex-TOS conjugate was synthesized by the coupling reaction of carboxyl group of $\alpha$-tocopherol succinate with hydroxyl group of dextran in the presence of $N, N^{\prime}$-dicyclohexylcarbodiimide (DCC) and 4-dimethylaminopyridine (DMAP). The conjugation scheme of Dex-TOS is presented in Figure 1a. By this reaction, various Dex-TOS copolymers with different degree substitution (DS) of TOS were synthesized by controlling the feed ratio of TOS to Dex. The DS of Dex-TOS, determined by ultraviolet (UV) spectrophotometry, was 3.0\% in this work. The DS of another Dex-TOS conjugate was $1.9 \%$. Above this reaction feed ratio, the produced Dex-TOS conjugates (DS: $>3.6 \%$ ) could not form nanoscaled particles in aqueous media. The chemical structure of Dex-TOS is confirmed by analysis of FT-IR and ${ }^{1} \mathrm{H}$ NMR spectra. Figure 2 shows the FT-IR spectra of dextran and Dex-TOS conjugate. For the Dex-TOS conjugation, as compared with dextran, new absorption band appeared at $1752 \mathrm{~cm}^{-1}$. The result was ascribed to the stretching of ester groups [21]. These results are evidence of the conjugation of TOS onto dextran.

The incorporation of TOS into dextran was further confirmed by ${ }^{1} \mathrm{H}$ NMR. As shown in Figure $1 \mathrm{~b}$, specific peaks of dextran were observed at 3.0-3.8 ppm and 4.5-5.0 ppm [22]. Compared with Dex, new proton peaks of TOS groups in Dex-TOS copolymer appeared at 0.83-2.0, 2.60 and 
$2.81 \mathrm{ppm}$ in ${ }^{1} \mathrm{H}$ NMR spectrum (Figure $1 \mathrm{~b}$ ). These results further confirmed that Dex-TOS conjugates were successfully synthesized.

(a)

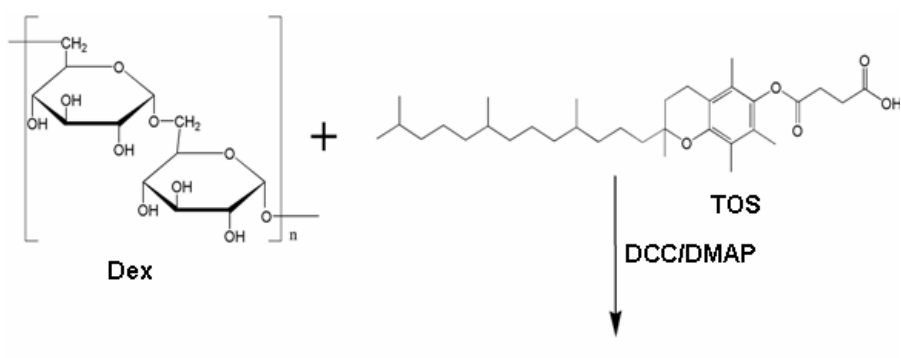

(b)

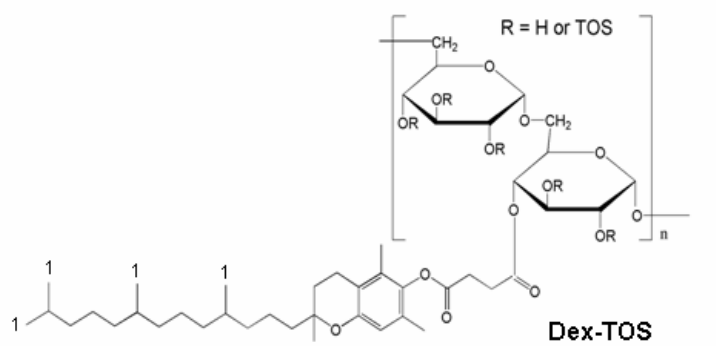

TOS

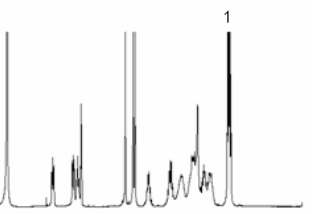

Dex

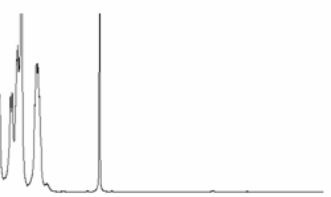

Dex-TOS

$\begin{array}{llllllllllllllllllll}9.0 & 8.5 & 8.0 & 7.5 & 7.0 & 6.5 & 6.0 & 5.5 & 5.0 & 4.5 & 4.0 & 3.5 & 3.0 & 2.5 & 2.0 & 1.5 & 1.0 & 0.5 & 0.0\end{array}$ $\mathrm{ppm}$

Figure 1. (a) Synthetic scheme of $\alpha$-tocopherol succinate conjugated dextran (Dex-TOS) conjugate and (b) ${ }^{1} \mathrm{H}$ nuclear magnetic resonance ( ${ }^{1} \mathrm{H}$ NMR) spectra of $\alpha$-tocopherol succinate (TOS), dextran (Dex) and Dex-TOS. 


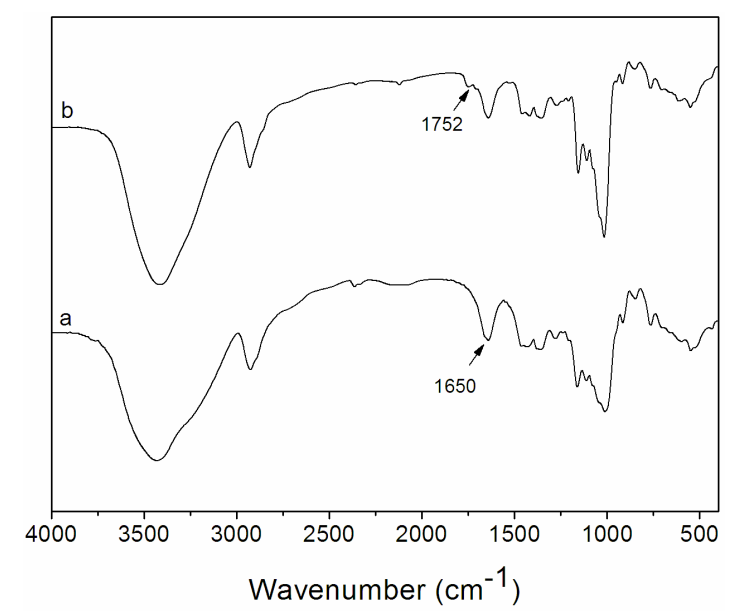

Figure 2. Fourier-transform infrared (FT-IR) spectra of (a) Dex and (b) Dex-TOS conjugate.

\subsection{Determination of Critical Micelle Concentration (CMC)}

Amphiphilic copolymers are able to form micelles in aqueous media. The core-shell structure of micelles are made during the process. The CMC value is a parameter indicative of the micelle's stability upon dilution. In order to determine the CMC of Dex-TOS, fluorescence measurement was carried out using pyrene as the hydrophobic fluorescence probe. Figure 3 showed the intensity ratio of $\mathrm{I}_{338} / \mathrm{I}_{333}$ vs. $\log \mathrm{C}$ of Dex-TOS conjugate for the pyrene excitation spectra. A flat region at extremely low concentration and a sigmoid change in the crossover region were observed. CMC can be obtained from the intersection of two straight lines [23]. The CMC of Dex-TOS was calculated to be $0.0034 \mathrm{mg} / \mathrm{mL}$, which was much lower than that of low molecular weight surfactants. The CMC value of another Dex-TOS conjugate (DS: $1.9 \%$ ) was $0.0075 \mathrm{mg} / \mathrm{mL}$. These results demonstrated that Dex-TOS conjugate was easy to form core-shell type nanoparticles in an aqueous environment. Moreover, we inferred that Dex-TOS micelles could remain stable even under highly diluted conditions and preserve their structure without dissociation in vivo.

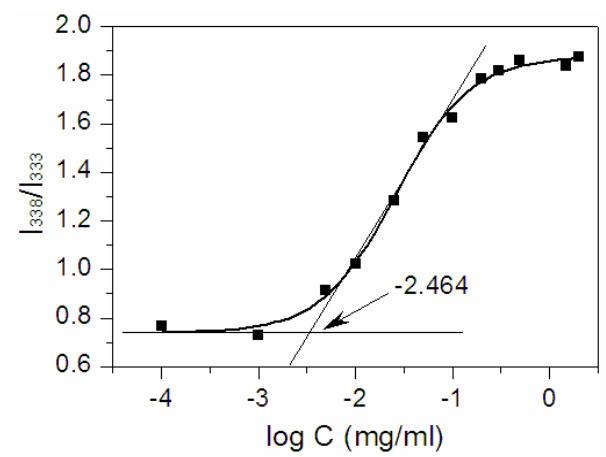

Figure 3. Polt of the intensity ratio $I_{338} / I_{333}$ (from pyrene excitation spectra of Dex-TOS) as a function of $\log C$.

\subsection{Characterization of Blank and Dex-TOS/Dox Micelles}

Blank micelles were prepared by dispersing Dex-TOS in an aqueous media. The particle size of Dex-TOS determined by dynamic light scattering (DLS) was $269 \mathrm{~nm}$. Dox was encapsulated into Dex-TOS micelles by a dialysis method. The physicochemical properties of Dex-TOS/Dox micelles are summarized in Table 1 . Based on the different ratios of feed drug to carrier $(0.5 / 10,1 / 10$, $1.5 / 10, \mathrm{w} / \mathrm{w})$, three kinds of Dex-TOS/Dox micelles were prepared, and named Dex-TOS-1/Dox, Dex-TOS-2/Dox and Dex-TOS-3/Dox, respectively. Their particle sizes determined by DLS were in 
the range of 295-325 nm. It was noticed that the hydrodynamic diameter was larger after loading the drug. This is due to the fact that the drug was solubilized inside the micelles. DOX was loaded into the micelles by the driving behavior of hydrophobic interaction, due to its low water solubility and interaction with the aromatic regions of TOS segments through $\pi-\pi$ stacking [24]. This result was consistent with the report by Liang et al. [25]. Moreover, it was found that drug-loading content and particle size of Dex-TOS/Dox micelles increased as the weight ratio of Dox to Dex-TOS increased. The Dox-loading content increased from $4.21 \%$ to $8.12 \%$, whereas the entrapment efficiency decreased from $87.9 \%$ to $58.9 \%$ at the same time. Based on the size and the drug loading property, the optimal ratio of drug to carrier $(1.5 / 10)$ was selected to prepare Dox-loaded micelles. Therefore, Dex-TOS-3/Dox micelles (with a drug loading content of $8.12 \%$ ) were used for the following studies.

Table 1. Physicochemical characteristics of Dex-TOS/Dox micelles.

\begin{tabular}{cccccc}
\hline Sample & Drug/Carrier $^{\mathbf{a}}$ & LC (\%) $^{\mathbf{b}}$ & EE (\%) $^{\mathbf{c}}$ & Size (nm) $^{\mathbf{d}}$ & PI $^{\mathbf{e}}$ \\
\hline Dex-TOS-1/Dox & $0.5 / 10$ & 4.21 & 87.9 & $295 \pm 12.3$ & $0.223 \pm 0.021$ \\
Dex-TOS-2/Dox & $1 / 10$ & 6.57 & 70.3 & $310 \pm 21.4$ & $0.126 \pm 0.013$ \\
Dex-TOS-3/Dox & $1.5 / 10$ & 8.12 & 58.9 & $325 \pm 25.6$ & $0.128 \pm 0.018$ \\
\hline
\end{tabular}

a The ratio of DOX to carrier, based on feed amount $(\mathrm{mg} / \mathrm{mg}){ }^{\mathbf{b}}$ loading content; ${ }^{\mathrm{c}}$ encapsulation efficiency;

d Measured by dynamic light scattering; ${ }^{\mathrm{e}}$ Polydispersity index.

Transmission electron microscopy (TEM) image depicted that Dex-TOS-3/Dox micelles were spherical in shape (Figure 4). The size of Dex-TOS-3/Dox micelles determined by DLS was $325 \mathrm{~nm}$, which was bigger than that observed by TEM. The difference was resulted from the sample preparation process. DLS analysis is in the hydrated state, while TEM sample was in the dried state.

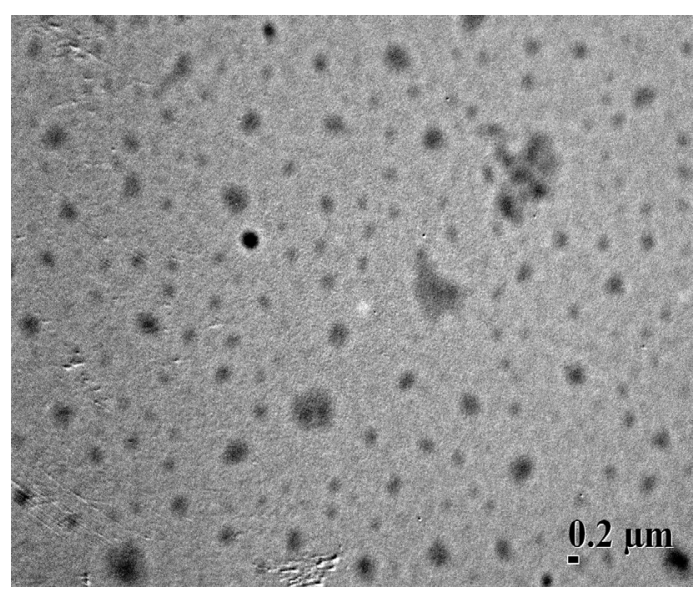

Figure 4. Transmission electron microscopy (TEM) image of Dex-TOS-3/Dox micelles $(\times 10,000)$.

\subsection{Differential Scanning Calorimetry (DSC)}

To study the physical existing status of Dox in Dex-TOS/Dox micelles, DSC analysis was performed on Dox, blank Dex-TOS, and Dex-TOS-3/Dox micelles. In the DSC thermogram (Figure 5), the Dox powder and physical mixtures showed a melting endothermic peak at $193.7^{\circ} \mathrm{C}$. However, endothermic peak of Dox in the curve of Dex-TOS/Dox micelles had disappeared. These results implied that Dox was essentially amorphous or molecular state in the micelles [26]. 


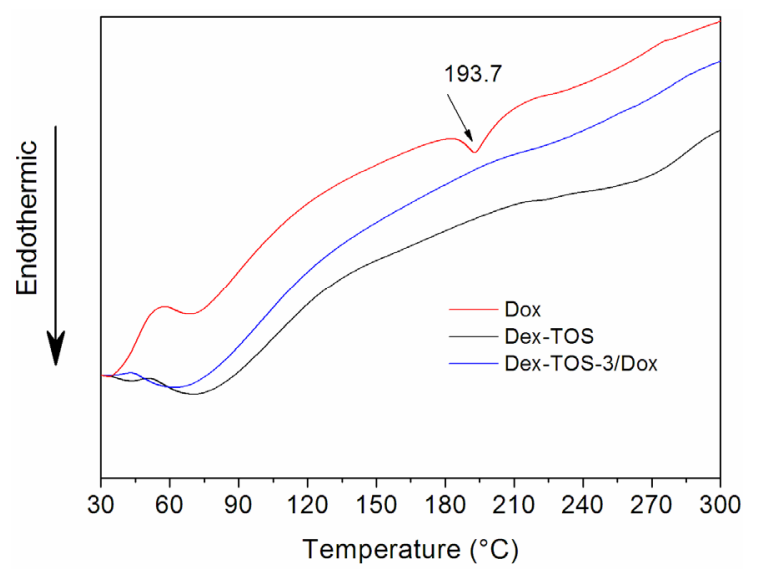

Figure 5. Differential scanning calorimetry (DSC) spectra of Dox, Dex-TOS, and Dex-TOS-3/Dox micelles.

\subsection{In Vitro Release of Dox-Loaded Micelles}

The release of Dox from Dex-TOS/Dox micelles was performed in phosphate buffer solution (PBS) at $\mathrm{pH} 7.4$, simulating the in vivo biological environment. The cumulative release profiles of Dox from the micelles were plotted in Figure 6. Dex-TOS-3/Dox micelles displayed the initial burst release for about $12 \mathrm{~h}$ and subsequent sustained release. The total amount of drug released from Dex-TOS-3/Dox was 50.2\% over $96 \mathrm{~h}$. The slow drug release was affected by either hydrophobic-hydrophobic interactions or van der Waals interactions between Dox molecules and the hydrophobic groups of the conjugates.

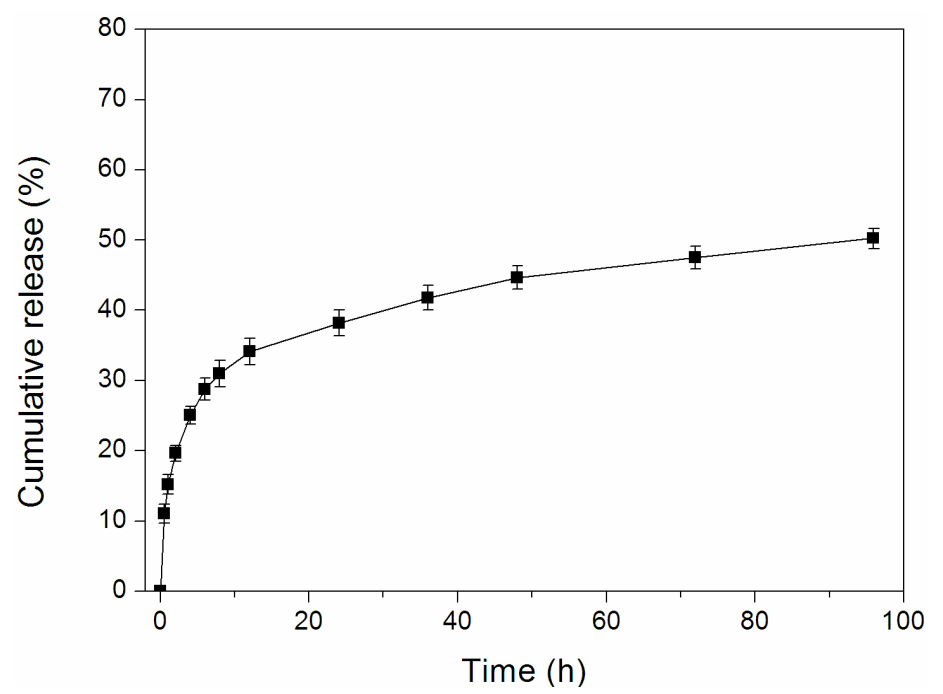

Figure 6. Release profile of Dox from Dex-TOS-3/Dox micelles at $37^{\circ} \mathrm{C}$ in phosphate buffer solution (PBS) at $\mathrm{pH} 7.4$.

\subsection{Confocal Laser Scanning Microscopy (CLSM) Observation}

The intracellular fate of Doxorubicin hydrochloride (Dox $\cdot \mathrm{HCl})$ or Dex-TOS-3/Dox micelles was monitored in KB cells by CLSM. As shown in Figure 7, the red fluorescence was emitted from Dox formulations and the blue fluorescence stained in nuclei was from Hoechst 33342 . Dox $\mathrm{HCl}$ incubation for $0.5 \mathrm{~h}$ showed red fluorescence mainly in the nuclei, while Dox fluorescence from Dex-TOS-3/Dox micelles was distributed mostly in cytoplasm. By contrast, red fluorescence emitted from Dox $\mathrm{HCl}$ was stronger than that of Dex-TOS-3/Dox micelles. With further incubation for 
$4 \mathrm{~h}$, Dox fluorescence intensities of these Dox formulations increased inside the cells. The red fluorescence from Dox $\mathrm{HCl}$ in the nuclei became more evident. In addition, the cells incubated with Dex-TOS-3/Dox micelles presented strong Dox fluorescence in the cytoplasm, and some fluorescence dots observed in the nuclei. After $12 \mathrm{~h}$ incubation, red intensities from both Dox formulations were higher than that for $4 \mathrm{~h}$. In addition, Dox $\mathrm{HCl}$ exhibited higher fluorescence than Dex-TOS-3/Dox micelles. Notably, it can be found that the fluorescence from Dex-TOS-3/Dox micelles significantly increased in the nuclei. These different results were ascribed to the different internalization ways between Dox $\mathrm{HCl}$ and Dex-TOS-3/Dox micelles. Dox $\mathrm{HCl}$ was entered into the cells in a passive diffusion way, whereas Dox-loaded micelles were transported into the cells by endocytosis manner [27]. Moreover, Dex-TOS-3/Dox micelles exhibited large particle size and high molecular weight. Dox-loaded micelles were difficult to directly transport into the nuclei [28,29]. The red fluorescence from Dex-TOS-3/Dox micelles in nuclei was mostly attributed to the release of free Dox molecules. As described above, Dox release from drug-loaded micelles was in a sustained way. Therefore, the Dox accumulation in the nucleus from Dox. $\mathrm{HCl}$ was higher than that from Dox-loaded micelles in $12 \mathrm{~h}$. Interestingly, TOS has the mitochondrial targetability and can participate in the mitochondrial signaling pathways. Thus high Dox fluorescence of Dex-TOS-3/Dox micelles distributed in the cytoplasm was beneficial to the improvement of apoptotic cell death. In addition, the experiments were performed in $24 \mathrm{~h}$ incubation (images not shown). However, great amount of cancer cells were dead in the plates of Dox $\mathrm{HCl}$ and Dex-TOS-3/Dox micelles.
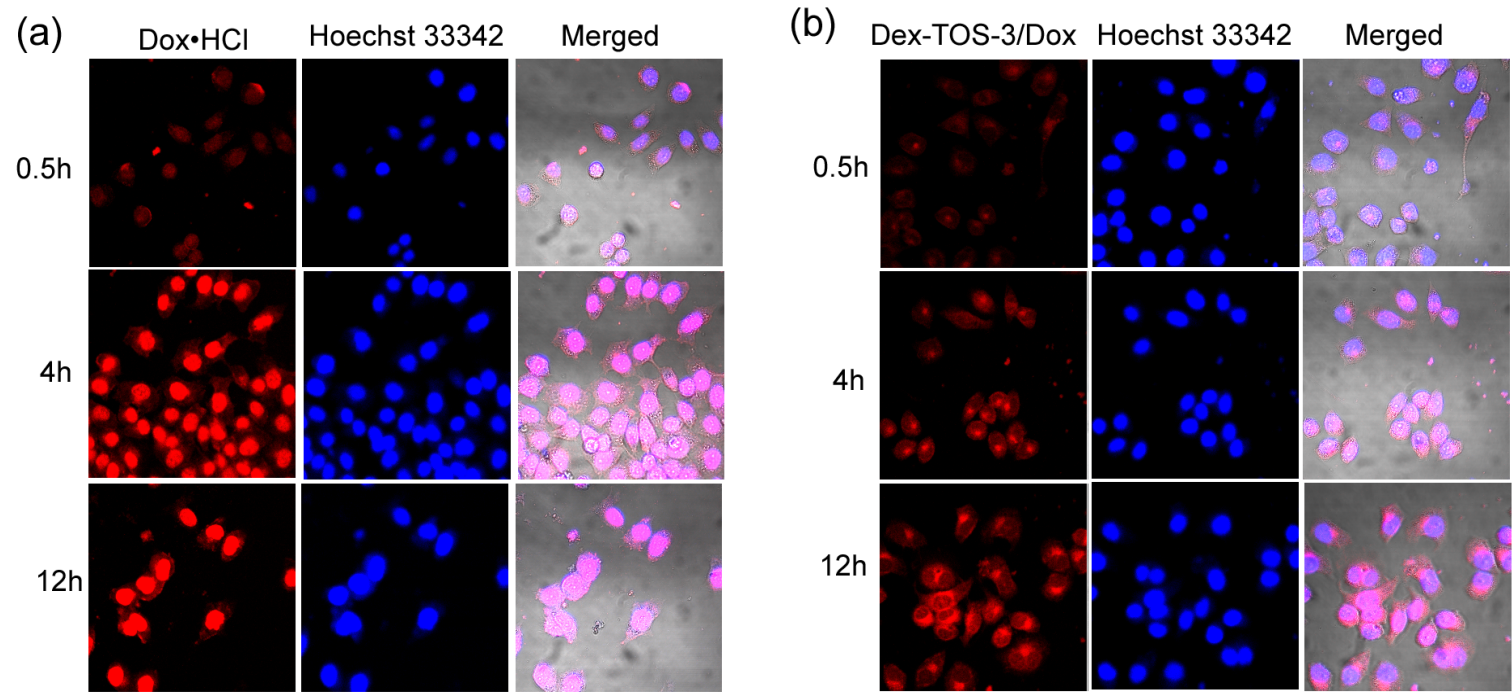

Figure 7. Confocal laser scanning microscopy (CLSM) images of human nasopharyngeal epidermoid carcinoma $(\mathrm{KB})$ cells after incubation with (a) doxorubicin hydrochloride (Dox $\cdot \mathrm{HCl})$ and (b) Dex-TOS-3/Dox micelles for 0.5, 4 and $12 \mathrm{~h}$.

\subsection{In Vitro Cytotoxicity Study}

The in vitro cytotoxicity of both Dox-loaded micelles and Dox $\mathrm{HCl}$ against $\mathrm{KB}$ cells were determined using 3-(4, 5-dimethyl-thiazol-2-yl)-2, 5-diphenyl-tetrazolium bromide (MTT) assay. As shown in Figure 8a, Dox formulations showed dose-dependent cytotoxicity to $\mathrm{KB}$ cells. Dox $\mathrm{HCl}$ and Dex-TOS-3/Dox micelles exhibited comparable cytotoxicity to KB cells at the same dose of Dox. The $\mathrm{IC}_{50}$ of Dox $\cdot \mathrm{HCl}$ and Dex-TOS-3/Dox micelles was 0.31 and $0.35 \mu \mathrm{g} / \mathrm{mL}$, respectively. As previously reported [30], Dox $\mathrm{HCl}$ can be quickly transported into cells by passive diffusion, while Dox-loaded micelles can be internalized in cells by endocytosis and Dox release is time-consuming process. As described above, only $45 \%$ of Dox were released from the drug carrier in $48 \mathrm{~h}$. The released Dox contributed to the cytotoxicity of Dox-loaded micelles. The actual cytotoxicity of Dox-loaded micelles should be greater along with the extension of time [31]. Notably, TOS can target 
mitochondria, leading to promote the mitochondria-specific apoptotic pathways [20]. Therefore, Dex-TOS can synergistically maximize the cytotoxic efficacy of the loaded DOX in the micelles via the targeting mitochondria. It was known that drug-loaded micelles can prevent premature drug release in blood and efficiently deliver it to tumor cells by EPR effect. Hence, it was speculated that the higher concentration of Dox from Dox-loaded micelles would be present in tumor site or tumor cells than that from Dox. $\mathrm{HCl}$ after intravenous injection of the same dose of Dox. In addition, the cell viabilities of blank Dex-TOS micelles against KB cells were $\geqslant 95 \%$, up to a concentration of $1 \mathrm{mg} / \mathrm{mL}$ (Figure $8 \mathrm{~b}$ ). These results revealed that Dex-TOS micelles were practically nontoxic and had good biocompatibility.
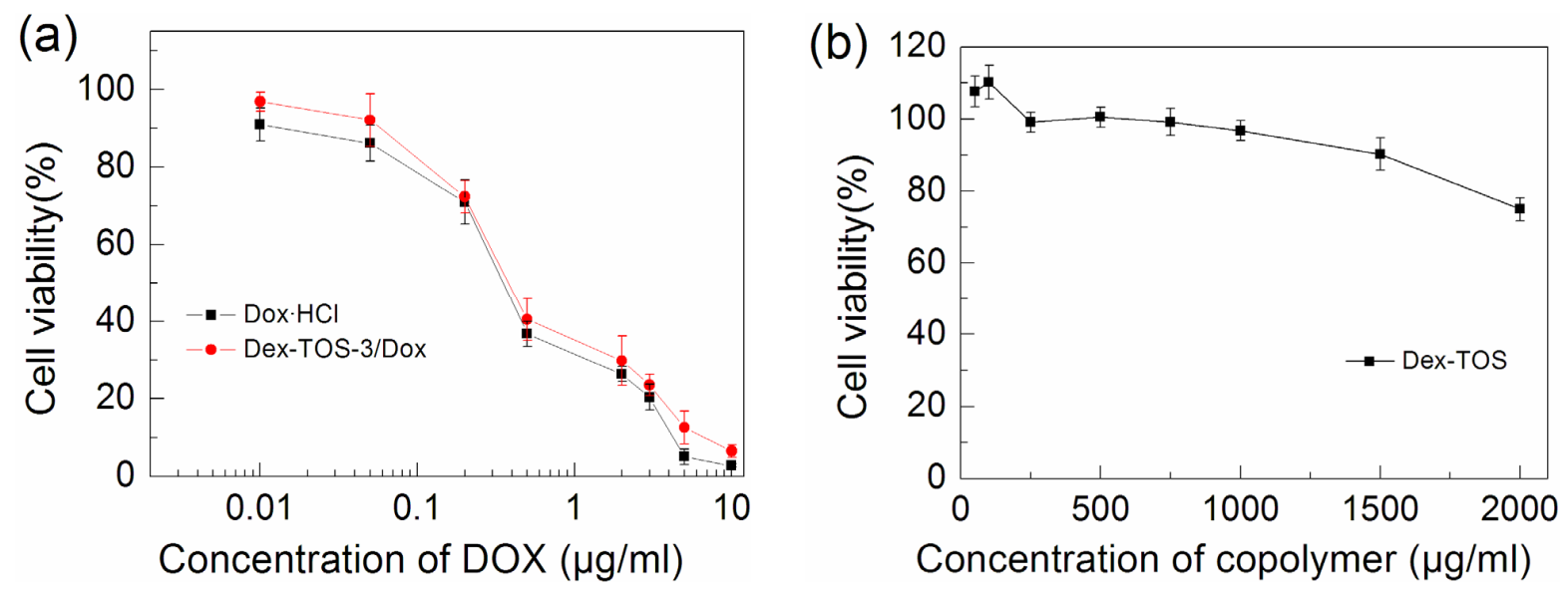

Figure 8. The cytotoxicity of (a) Dox $\cdot \mathrm{HCl}$, Dex-TOS-3/Dox micelles, and (b) blank Dex-TOS micelles against $\mathrm{KB}$ cells after $48 \mathrm{~h}$ incubation.

\section{Experimental Section}

\subsection{Materials}

Dextran (Dex, $40 \mathrm{kDa}), \alpha$-tocopherol succinate (TOS), $N$, N'-dicyclohexylcarbodiimide (DCC), and 4-dimethylaminopyridine (DMAP) were purchased from Sigma-Aldrich (St. Louis, MO, USA). Anhydrous dimethyl sulfoxide (DMSO) and pyrene were provided by Acros Organics (Beijing, China). Doxorubicin hydrochloride (Dox. $\mathrm{HCl}$ ) was obtained from Beijing Huafeng United Technology Co., Ltd. (Beijing, China). Human nasopharyngeal epidermoid carcinoma (KB) cells were purchased from the Institute of Biochemistry and Cell Biology of Chinese Academy of Sciences (Shanghai, China). RPMI 1640 medium and trypsin-EDTA were obtained from Jinuo biotechnology company (Hangzhou, China). Fetal bovine serum (FBS) was from Sijiqing Biologic Co. Ltd. (Zhejiang, China). 3-(4, 5-Dimethyl-thiazol-2-yl)-2, 5-diphenyl-tetrazolium bromide (MTT) was purchased from Sigma-Aldrich (St. Louis, MO, USA). All other chemicals were of analytical grade.

\subsection{Synthesis of Dex-TOS Conjugate}

Five hundred milligrams dextran and $60 \mathrm{mg}$ DMAP were dissolved in $15 \mathrm{~mL}$ anhydrous DMSO. TOS (327 mg) and DCC (382 mg) were dissolved in $100 \mathrm{~mL}$ anhydrous DMSO and stirred for $4 \mathrm{~h}$ under the protection of nitrogen. TOS/DCC solution was slowly added to the dextran/DMAP solution. This mixed solution was stirred to react for $48 \mathrm{~h}$ in nitrogen gas at room temperature. After that, this solution was filtered to remove the byproducts and dialyzed against distilled water for 2 days. The resultant solution was freeze-dried. Dextran is insoluble in anhydrous ethanol. The lyophilized product was dispersed in anhydrous ethanol under the help of sonication to remove unreacted TOS. Then the mixture was centrifuged at 12,000 rpm for $5 \mathrm{~min}$ (Sigma laboratory centrifuges 3K18, Osterode, Germany). The ethanol solution was discarded. The precipitated product was dissolved 
in water and dialyzed against distilled water for another 2 days. The dialyzed solution was filtered through a $0.8-\mu \mathrm{m}$ membrane and lyophilized. The white product Dex-TOS was obtained.

FT-IR spectrum of Dex-TOS was recorded on a Fourier-transform infrared spectrometer (Vertex 70, Bruker Corporation, Ettlingen, Germany). Dex or Dex-TOS was thoroughly ground with exhaustively dried KBr. The composition of Dex-TOS was further confirmed by ${ }^{1} \mathrm{H}$ NMR spectra using a NMR spectrometer (Avance DMX500, Bruker Corporation, Ettlingen, Germany). DMSO- $d 6$ was used as solvent.

The substitution degree (DS) of TOS to dextran was expressed as mol \% vs. 100 glucose groups. The extent of TOS conjugation was determined by ultraviolet (UV) spectrophotometry as previously described by Mandracchia et al. [18]. The absorbance wavelength is set at $286 \mathrm{~nm}$. The calibration curve of TOS in DMSO was made in the concentration range $60-240 \mu \mathrm{g} / \mathrm{mL}\left(R^{2}=0.9962\right)$. Twenty-seven milligrams of Dex-TOS were dissolved in $15 \mathrm{~mL}$ DMSO. The absorbance value was analyzed by an UV spectrophotometer (TU-1901, Beijing Purkinje General Instrument Co., Ltd., Beijing, China).

\subsection{Determination of Critical Micelle Concentration (CMC)}

Fluorescence spectroscopy was employed to study the micellization property of Dex-TOS. Briefly, Dex-TOS conjugate suspension was adjusted to various concentrations. A known amount of pyrene in acetone was added to $10-\mathrm{mL}$ vials, and acetone was evaporated at $40{ }^{\circ} \mathrm{C}$. Then, $10 \mathrm{~mL}$ of various concentrations of sample suspension were added to each vial, and heated at $50{ }^{\circ} \mathrm{C}$ for $10 \mathrm{~h}$ to equilibrate the pyrene and the micelles, and remained undisturbed to cool overnight at room temperature. The final concentration of pyrene was $6.0 \times 10^{-7} \mathrm{M}$. Steady-state fluorescent spectra were measured by fluorescence spectrophotometer (Hitachi F-4500, Hitachi Ltd., Tokyo, Japan) with a slit width of $2.5 \mathrm{~nm}$. The excitation and emission wavelength was set at 339 and $390 \mathrm{~nm}$, respectively.

\subsection{Preparation of Dox-loaded Micelles}

The Dox-loaded Dex-TOS micelles were prepared by a dialysis method. Briefly, Dex-TOS conjugate (100 mg) was dissolved in $2 \mathrm{~mL}$ of DMSO. Different amounts of doxorubicin hydrochloride $(5,10$ or $15 \mathrm{mg})$ were separately dissolved in $2 \mathrm{~mL}$ DMSO with 3 equivalent molar ratio of triethylamine, and stirred overnight under the dark condition. Then Dox solution was added to the above Dex-TOS solution. The mixture solution was magnetically stirred for $6 \mathrm{~h}$, and placed into the dialysis bag (MWCO: $7 \mathrm{kDa}$ ) for dialysis against distilled water for $24 \mathrm{~h}$. After that, the dialysis solution was filtered through a $0.8 \mu \mathrm{m}$ membrane and lyophilized.

\subsection{Characterization of Blank and Dex-TOS/Dox Micelles}

The mean diameter and size distribution of blank and Dex-TOS/Dox micelles were analyzed by dynamic light scattering (90Plus, Brookhaven Instruments Corp., New York, NY, USA). The morphology of Dex-TOS micelles encapsulating Dox was observed using a transmission electron microscopy (JEM-1230, Jeol, Tokyo, Japan). A drop of sample solution was placed onto a 300-mesh copper grid coated with carbon and the extra solution was blotted with filter paper, followed by air-drying. Observation was performed at $80 \mathrm{kV}$.

The drug loading content $(L C)$ and encapsulation efficiency $(E E)$ of Dex-TOS/Dox micelles were determined by extracting the drug from the micelles and using UV method. Dex-TOS/Dox micelles were dissolved in aqueous solution and disrupted by the addition of DMSO. Dox concentration was measured using an UV spectrophotometer at $481 \mathrm{~nm}$. The $L C$ and EE of Dex-TOS/Dox micelles were calculated with the following equations:

$$
L C(\%)=\frac{\text { Dox weight in the micelles }}{\text { weight of Dex }- \text { TOS/Dox micelles }} \times 100
$$




$$
E E(\%)=\frac{\text { Dox weight in the micelles }}{\text { feed Dox weight }} \times 100
$$

\subsection{DSC Analysis}

In order to evaluate the status of Dox in Dex-TOS/Dox micelles, DSC analysis was performed by STA 8000 Thermal Analyzer (PerkinElmer, Waltham, MA, USA). Dox, Dex-TOS or Dex-TOS/Dox micelles were analyzed at heating temperature ranging from 30 to $300^{\circ} \mathrm{C}$ with a rate of $10^{\circ} \mathrm{C} \mathrm{min}$.

\subsection{In Vitro Release of Dox-loaded Micelles}

Dox release from Dox-loaded micelles was investigated in vitro by a dialysis method in phosphate buffered saline (PBS, pH 7.4). Briefly, $1 \mathrm{~mL}$ of Dox-loaded micelles was placed in a dialysis bag (MWCO: $7 \mathrm{kDa}$ ) and dialyzed against $20 \mathrm{~mL}$ of PBS medium. The condition was set at $37^{\circ} \mathrm{C}$ and maintained at $100 \mathrm{rpm}$ in an air-bath shaker. At predetermined time intervals, the total sample was removed and replaced with $20 \mathrm{~mL}$ of fresh PBS media. The amount of Dox released from the micelles was investigated by fluorescence spectrophotometer (Hitachi F-4500, Hitachi Ltd., Tokyo, Japan). An excitation wavelength of $470 \mathrm{~nm}$ and an emission wavelength of $585 \mathrm{~nm}$ were applied.

\subsection{Confocal Laser Scanning Microscopy (CLSM) Observation}

CLSM was adopted to observe the intracellular distribution of Dox. Briefly, KB cells were seeded at a density of $3 \times 10^{5}$ cells/well in 6-well plates (Costar, Corning, NY, USA) overnight at $37{ }^{\circ} \mathrm{C}$ in $5 \% \mathrm{CO}_{2}$. After removed the cultured media, Dox. $\mathrm{HCl}$ or Dex-TOS/Dox micelles (final Dox concentration: $10 \mu \mathrm{g} / \mathrm{mL}$ ) in RPMI 1640 medium supplemented with 10\% FBS were added. After $0.5,4$ or $12 \mathrm{~h}$ incubation, the cells were washed three times with PBS (pH 7.4) and fixed in $4 \%$ paraformaldehyde solution for $10 \mathrm{~min}$. Further, the cells were treated with Hoechst $33342(5 \mu \mathrm{g} / \mathrm{mL})$ for nuclei staining. After $20 \mathrm{~min}, \mathrm{~KB}$ cells were washed with PBS. The cells were examined by a Zeiss LSM-510 confocal microscope (ZEISS, Jena, Germany) under the identical settings.

\subsection{In Vitro Cytotoxicity Study}

The cytotoxicity of blank or Dox-loaded micelles was evaluated in vitro by the MTT assays. KB cells were seeded at a density of $4 \times 10^{3}$ cells/well in 96-well plates and cultured overnight. Then, the culture medium was removed. Various concentrations of blank micelles, Dox $\cdot \mathrm{HCl}$, or Dex-TOS/Dox micelles which were dispersed in RPMI 1640 medium containing 10\% FBS were added. After $48 \mathrm{~h}$ treatment, the medium in each well was discarded. One hundred milliliters of fresh culture medium and $20 \mu \mathrm{L}$ of MTT solution ( $5 \mathrm{mg} / \mathrm{mL}$ in PBS) were added. The cells were incubated for $4 \mathrm{~h}$, and the medium was replaced by $150 \mu \mathrm{L}$ DMSO to dissolve the purple crystals. After $15 \mathrm{~min}$, the optical densities at $570 \mathrm{~nm}$ were measured with a microplate reader (Thermo Fisher Scientific, Waltham, MA, USA). Cells cultured in RPMI 1640 medium containing 10\% FBS were used as controls.

\section{Conclusions}

Dex-TOS conjugate was successfully synthesized and characterized. The Dex-TOS conjugate could self-assemble to form nanosized micelles in aqueous medium and show low CMC. The release profile of Dex-TOS/Dox micelles showed that Dox could be released rapidly in the first $12 \mathrm{~h}$ and the sustaining release could last for about $96 \mathrm{~h}$. Dox-loaded micelles could be internalized in KB cells by endocytosis manner. Dex-TOS/Dox micelles exhibited comparable cytotoxicity against KB cells in comparison with Dox. $\mathrm{HCl}$. Furthermore, blank Dex-TOS micelles showed good biocompatibility. Taken together, the results suggest that Dex-TOS micelles have potential as drug delivery vehicles for cancer therapy. 
Acknowledgments: This work was financially supported by National Natural Science Foundation of China (81001418), Natural Science Foundation of Jiangxi Province (20151BAB205081), and Scientific Research Fund of Jiangxi Health Department (20157105).

Author Contributions: Jingmou Yu and Hao Huang conceived and designed the experiments; Yufeng Zhou, Wencong Chen and Gan Luo are research students who carried out the laboratory test; and Jin Ren, Lifang Zhang and $\mathrm{Lu} \mathrm{Lu}$ analyzed the data and discussed the experiment. Jingmou Yu wroted the manuscript and Hao Huang reviewed the study.

Conflicts of Interest: The authors declare no conflicts of interest in this work.

\section{References}

1. Li, Y.L.; Zhu, L.; Liu, Z.; Cheng, R.; Meng, F.; Cui, J.H.; Ji, S.J.; Zhong, Z. Reversibly stabilized multifunctional dextran nanoparticles efficiently deliver doxorubicin into the nuclei of cancer cells. Angew. Chem. Int. Ed. 2009, 48, 9914-9918. [CrossRef] [PubMed]

2. Zhang, A.; Zhang, Z.; Shi, F.; Xiao, C.; Ding, J.; Zhuang, X.; He, C.; Chen, L.; Chen, X. Redox-sensitive shell-crosslinked polypeptide-block-polysaccharide micelles for efficient intracellular anticancer drug delivery. Macromol. Biosci. 2013, 13, 1249-1258. [CrossRef] [PubMed]

3. Wang, H.; Wang, S.; Liu, Z.; Dong, C.; Yang, J.; Gong, X.; Chang, J. Upconverting crystal/dextran-g-DOPE with high fluorescence stability for simultaneous photodynamic therapy and cell imaging. Nanotechnology 2014, 25. [CrossRef] [PubMed]

4. Aumelas, A.; Serrero, A.; Durand, A.; Dellacherie, E.; Leonard, M. Nanoparticles of hydrophobically modified dextrans as potential drug carrier systems. Colloid. Surface. B 2007, 59, 74-80. [CrossRef] [PubMed]

5. Thambi, T.; You, D.G.; Han, H.S.; Deepagan, V.G.; Jeon, S.M.; Suh, Y.D.; Choi, K.Y.; Kim, K.; Kwon, I.C.; Yi, G.-R.; et al. Bioreducible carboxymethyl dextran nanoparticles for tumor-targeted drug delivery. Adv. Health. Mater. 2014, 3, 1829-1838. [CrossRef] [PubMed]

6. Du, Y.Z.; Weng, Q.; Yuan, H.; Hu, F.Q. Synthesis and antitumor activity of stearate-g-dextran micelles for intracellular doxorubicin delivery. ACS Nano 2010, 4, 6894-6902. [CrossRef] [PubMed]

7. Mochida, Y.; Cabral, H.; Miura, Y.; Albertini, F.; Fukushima, S.; Osada, K.; Nishiyama, N.; Kataoka, K. Bundled assembly of helical nanostructures in polymeric micelles loaded with platinum drugs enhancing therapeutic efficiency against pancreatic tumor. ACS Nano 2014, 8, 6724-6738. [CrossRef] [PubMed]

8. Sun, T.; Zhang, Y.S.; Pang, B.; Hyun, D.C.; Yang, M.; Xia, Y. Engineered nanoparticles for drug delivery in cancer therapy. Angew. Chem. Int. Ed. 2014, 53, 12320-12364. [CrossRef] [PubMed]

9. Liang, Y.; Su, Z.; Yao, Y.; Zhang, N. Preparation of $\mathrm{pH}$ sensitive Pluronic-docetaxel conjugate micelles to balance the stability and controlled release issues. Materials 2015, 8, 379-391. [CrossRef]

10. Yu, J.; Xie, X.; Wu, J.; Liu, Y.; Liu, P.; Xu, X.; Yu, H.; Lu, L.; Che, X. Folic acid conjugated glycol chitosan micelles for targeted delivery of doxorubicin: preparation and preliminary evaluation in vitro. J. Biomater. Sci. Polym. Ed. 2013, 24, 606-620. [CrossRef]

11. Biswas, S.; Torchilin, V.P. Nanopreparations for organelle-specific delivery in cancer. Adv. Drug. Deliver. Rev. 2014, 66, 26-41. [CrossRef] [PubMed]

12. Matsumura, Y.; Maeda, H. A new concept for macromolecular therapeutics in cancer chemotherapy: Mechanism of tumoritropic accumulation of proteins and the antitumor agent smancs. Cancer Res. 1986, 46, 6387-6392. [PubMed]

13. Palao-Suay, R.; Aguilar, M.R.; Parra-Ruiz, F.J.; Fernandez-Gutierrez, M.; Parra, J.; Sanchez-Rodriguez, C.; Sanz-Fernandez, R.; Rodriganez, L.; San Roman, J. Anticancer and antiangiogenic activity of surfactant-free nanoparticles based on self-assembled polymeric derivatives of vitamin E: Structure-activity relationship. Biomacromolecules 2015, 16, 1566-1581. [CrossRef] [PubMed]

14. Won, Y.W.; Yoon, S.M.; Sonn, C.H.; Lee, K.M.; Kim, Y.H. Nano self-assembly of recombinant human gelatin conjugated with alpha-tocopheryl succinate for Hsp90 inhibitor, 17-AAG, delivery. ACS Nano 2011, 5, 3839-3848. [CrossRef] [PubMed]

15. Duhem, N.; Danhier, F.; Preat, V. Vitamin E-based nanomedicines for anti-cancer drug delivery. J. Control. Release 2014, 182, 33-44. [CrossRef] [PubMed]

16. Danhier, F.; Kouhe, T.T.B.; Duhem, N.; Ucakar, B.; Staub, A.; Draoui, N.; Feron, O.; Preat, V. Vitamin E-based micelles enhance the anticancer activity of doxorubicin. Int. J. Pharm. 2014, 476, 9-15. [CrossRef] [PubMed] 
17. Duhem, N.; Rolland, J.; Riva, R.; Guillet, P.; Schumers, J.M.; Jerome, C.; Gohy, J.F.; Preat, V. Tocol modified glycol chitosan for the oral delivery of poorly soluble drugs. Int. J. Pharm. 2012, 423, 452-460. [CrossRef] [PubMed]

18. Mandracchia, D.; Tripodo, G.; Latrofa, A.; Dorati, R. Amphiphilic inulin-D- $\alpha$-tocopherol succinate (INVITE) bioconjugates for biomedical applications. Carbohyd. Polym. 2014, 103, 46-54. [CrossRef] [PubMed]

19. Tripodo, G.; Pasut, G.; Trapani, A.; Mero, A.; Lasorsa, F.M.; Chlapanidas, T.; Trapani, G.; Mandracchia, D. Inulin-D- $\alpha$-tocopherol succinate (INVITE) nanomicelles as a platform for effective intravenous administration of curcumin. Biomacromolecules 2015, 16, 550-557. [CrossRef] [PubMed]

20. Liang, D.; Wang, A.T.; Yang, Z.Z.; Liu, Y.J.; Qi, X.R. Enhance cancer cell recognition and overcome drug resistance using hyaluronic acid and $\alpha$-tocopheryl succinate based multifunctional nanoparticles. Mol. Pharm. 2015, 12, 2189-2202. [CrossRef] [PubMed]

21. Li, M.; Tang, Z.; Lv, S.; Song, W.; Hong, H.; Jing, X.; Zhang, Y.; Chen, X. Cisplatin crosslinked pH-sensitive nanoparticles for efficient delivery of doxorubicin. Biomaterials 2014, 35, 3851-3864. [CrossRef] [PubMed]

22. Yuan, X.B.; Li, H.; Zhu, X.X.; Woo, H.G. Self-aggregated nanoparticles composed of periodate-oxidized dextran and cholic acid: Preparation, stabilization and in-vitro drug release. J. Chem. Technol. Biot. 2006, 81, 746-754. [CrossRef]

23. Zhang, J.; Ma, P.X. Polymeric core-shell assemblies mediated by host-guest interactions: Versatile nanocarriers for drug delivery. Angew. Chem. Int. Ed. 2009, 48, 964-968. [CrossRef] [PubMed]

24. Catenacci, L.; Mandracchia, D.; Sorrenti, M.; Colombo, L.; Serra, M.; Tripodo, G. In-solution structural considerations by ${ }^{1} \mathrm{H}$ NMR and solid-state thermal properties of inulin-D- $\alpha$-tocopherol succinate (INVITE) micelles as drug delivery systems for hydrophobic drugs. Macromol. Chem. Phys. 2014, 215, 2084-2096. [CrossRef]

25. Liang, N.; Sun, S.; Li, X.; Piao, H.; Piao, H.; Cui, F.; Fang, L. $\alpha$-Tocopherol succinate-modified chitosan as a micellar delivery system for paclitaxel: Preparation, characterization and in vitro/in vivo evaluations. Int. J. Pharm. 2012, 423, 480-488. [CrossRef] [PubMed]

26. Cao, H.; Wang, Y.; He, X.; Zhang, Z.; Yin, Q.; Chen, Y.; Yu, H.; Huang, Y.; Chen, L.; Xu, M.; et al. Codelivery of sorafenib and curcumin by directed self-assembled nanoparticles enhances therapeutic effect on hepatocellular carcinoma. Mol. Pharm. 2015, 12, 922-931. [CrossRef] [PubMed]

27. Torchilin, V.P. Fluorescence microscopy to follow the targeting of liposomes and micelles to cells and their intracellular fate. Adv. Drug Deliver. Rev. 2005, 57, 95-109. [CrossRef] [PubMed]

28. Yu, J.; Xie, X.; Zheng, M.; Yu, L.; Zhang, L.; Zhao, J.; Jiang, D.; Che, X. Fabrication and characterization of nuclear localization signal-conjugated glycol chitosan micelles for improving the nuclear delivery of doxorubicin. Int. J. Nanomed. 2012, 7, 5079-5090. [CrossRef]

29. Yu, J.; Xie, X.; Xu, X.; Zhang, L.; Zhou, X.; Yu, H.; Wu, P.; Wang, T.; Che, X.; Hu, Z. Development of dual ligand-targeted polymeric micelles as drug carriers for cancer therapy in vitro and in vivo. J. Mater. Chem. B 2014, 2, 2114-2126. [CrossRef]

30. Cui, C.; Xue, Y.N.; Wu, M.; Zhang, Y.; Yu, P.; Liu, L.; Zhuo, R.X.; Huang, S.W. Cellular uptake, intracellular trafficking, and antitumor efficacy of doxorubicin-loaded reduction-sensitive micelles. Biomaterials 2013, 34, 3858-3869. [CrossRef] [PubMed]

31. Guo, H.; Lai, Q.; Wang, W.; Wu, Y.; Zhang, C.; Liu, Y.; Yuan, Z. Functional alginate nanoparticles for efficient intracellular release of doxorubicin and hepatoma carcinoma cell targeting therapy. Int. J. Pharm. 2013, 451, 1-11. [CrossRef] [PubMed]

(C) 2015 by the authors; licensee MDPI, Basel, Switzerland. This article is an open access article distributed under the terms and conditions of the Creative Commons by Attribution (CC-BY) license (http:/ / creativecommons.org/licenses/by/4.0/). 